\title{
Supporting improvements to undergraduate STEM instruction: an emerging model for understanding instructional change teams
}

\author{
Alice Olmstead ${ }^{1 *}$ (D) Andrea Beach² and Charles Henderson²
}

\begin{abstract}
Background: Instructional change efforts involving teams of change agents are becoming increasingly prevalent at higher education institutions across the US. Teams may be able to make more lasting and high-quality changes to STEM courses than instructors working alone. But team-based change efforts are also risky. They tend to require more resources than individually focused efforts, and there are many ways in which teams can fail to achieve their goals. So far, research on how change leaders can best support instructional change teams has been extremely limited. We lack a context-specific model that can help us to understand how, when, and why instructional change teams are likely to generate positive outcomes. This study begins to address this limitation by exploring the decisions that project leaders make when establishing supports for instructional change teams.

Results: We use a grounded theory approach to analyze interviews with 28 leaders of team-based instructional change projects and connect our findings to existing literature about teams in other contexts. We identify five categories of key team inputs: the nature of the task, who participates, process constraints, external engagement, and access to resources. We situate these team inputs in a preliminary model of instructional change teams. In our model, we posit that these team inputs are consequential for how teams work together and for how teams think and feel about their work. This in turn leads to various kinds of team outcomes.

Conclusions: Our current model lays out key decisions that project leaders make when setting up instructional change teams. It also highlights the mechanisms by which instructional change team inputs can lead to various outcomes. We argue that this can guide change leaders to have productive conversations when initiating new teams or troubleshooting collaboration challenges of existing teams. Our research also provides a foundation for deeper exploration into how teams work together and the consequences for team outcomes. In particular, future research focused on the perspectives of team members could test and build on this initial model.
\end{abstract}

Keywords: Instructional change, Higher education, Teams, Organizational change

\section{Introduction}

A growing number of higher education leaders and funding agencies have started to focus on supporting teams of change agents as a way to improve undergraduate STEM education (Weaver et al. 2016). This differs from past approaches that focus on individual instructors as the

*Correspondence: alice.olmstead@txstate.edu

'Department of Physics, Texas State University, 601 University Drive, San Marcos, 78666, USA

Full list of author information is available at the end of the article unit of change and from approaches that focus on enacting policies (Henderson et al. 2011). Teams of instructors and others (students, administrators, postdoctoral fellows, etc.) can often make more lasting, expansive changes than either individual instructors or policy makers alone. In part, this is because teams have more control over their local environment than any one instructor (Austin 2011; Gehrke and Kezar 2017; Elrod and Kezar 2017; Reinholz and Apkarian 2018). For example, a departmental team can work to develop coordinated improvements to 
multiple, interdependent courses that are taught by many instructors (e.g., Manogue et al. 2001; Marbach-Ad 2007; Matz and Jardeleza 2016; Reinholz and Apkarian 2018). Similarly, a departmental team can work continuously on a single course that is taught by different instructors in different semesters, thus sustaining and refining improvements to the course over time (e.g., Chasteen et al. (2015)). In contrast to purely top-down approaches, team-based approaches can also allow instructors to develop a sense of ownership over the changes and thus feel more committed to sustaining them (Weaver et al. 2016; Dee and Leisyte 2016; Elrod and Kezar 2017; Reinholz and Apkarian 2018).

Teams might also be better able to improve undergraduate STEM instruction than individuals because of the potential benefits of collaborative problem-solving. Literature in other contexts shows that teams can be "smarter" than individuals, particularly when solving complex tasks (Karlgaard and Malone 2015; Jehn et al. 1999; Woolley et al. 2010). We anticipate that similar cognitive advantages can emerge when teams organize around improving STEM instruction.

Despite potential benefits, team-based approaches to instructional change are also risky. Team-based instructional change efforts can use significant individual, departmental, institutional, and/or external resources (e.g., time, energy, and money) (Weaver et al. 2016). Yet, we know that teams in general are often less successful than one might hope (Mannix and Neale 2005; Karlgaard and Malone 2015). For example, teams may struggle to make timely progress because of communication challenges (Stasser et al. 2000; Karlgaard and Malone 2015), fall apart because of interpersonal conflict (Lau and Murnighan 1998; Jehn et al. 1999; Mannix and Neale 2005), and/or fail to support the participation of all team members (Keltner et al. 2003).

We argue that there is a need for new research on how higher education teams work together and why this happens, including how these teams avoid or overcome collaboration challenges. Developing shared vision, which encompasses most team-based change, was the least studied approach out of the four major approaches to improving undergraduate STEM instruction identified by Henderson et al. (2011). Scholarly work has expanded somewhat since then, but remains quite limited (Gast et al. 2017). In particular, recent publications centered on teams tend to be localized accounts of instructional change that were not designed to investigate how such teams can be successful at other institutions (Gast et al. 2017).

While the literature about teams in other contexts (tech companies, hospitals, the military, etc.) can provide valuable insights, that literature alone is not sufficient to compensate for a lack of context-specific research in higher education settings. The teams literature is quite expansive and is primarily aimed at those who study and practice business management (Guzzo and Dickson 1996; Ilgen et al. 2005; Karlgaard and Malone 2015; Mannix and Neale 2005). It is not clear a priori which findings about teams are most applicable here and how they would translate across contexts. Distinctive aspects of STEM higher education could play a strong role in shaping how teams are set up, how they work together, and what kinds of outcomes are seen as important.

Some recent research on instructional change (e.g., Kezar 2001; Kezar 2014; Dee and Leiśytè 2016; Corbo et al. 2016; Reinholz and Apkarian 2018) provides proof-of-concept that theories from business management can be useful in higher education contexts, but need to be adapted first. For example, Reinholz and Apkarian (2018) show that the four "frames" from an organizational learning theory-structures, symbols, people, and power-can shed light on departmental change processes. In doing so, they also show that interpretive work is necessary to understand how particular aspects of academic departments (course releases, collection of institutional data, instructor autonomy, formal departmental leadership, etc.) fit within each frame. Such research focuses on understanding organizational change in higher education at a systemic level, rather than focusing on the team level. But it demonstrates both that some principles hold across many organizational contexts and that some aspects of higher education are unique.

Our article represents an early stage in an exploratory study focused on instructional change teams. We define instructional change teams as those that are working to create or redesign a course or set of courses. Here, we begin to articulate and unpack the range of concrete decisions that leaders make when setting up or supporting such teams. Our analysis is based on interviews with leaders of team-based instructional change projects at higher education institutions across the US. The research presented here is primarily descriptive and intended to lay groundwork for future studies. We address the research question: What are key factors that influence how instructional change teams work together to improve undergraduate STEM courses within a department or institution?

\section{Methods}

\section{Grounded theory}

Because there has been little research conducted on how instructional change teams work together and why they work in these ways, we use research methods that support us in discovering new ideas without being overly constrained by the past work. Specifically, we draw on grounded theory: a research methodology characterized by openness to new ideas, a focus on explanatory power, and iterative data collection and analysis (Glaser and 
Strauss 2017; Gibson and Hartman 2013). Consistent with grounded theory, we strongly prioritize our own empirical data in our initial theory-building.

Scholars who use grounded theory also advocate for layering new information onto initial theories in ways that make them increasingly general (Gibson and Hartman 2013). We think that connecting to existing literature from other contexts is an important step in laying the groundwork for later generalization. But as Gibson and Hartman (2013) highlight in their synthesis of the many interpretations of grounded theory, scholars who describe this methodology often do not provide clear guidance on how and when to draw on prior literature. Those who do discuss the use of literature argue that detailed knowledge of past research should be avoided until late stages of analysis so that theory can emerge more organically from the data.

With these considerations in mind, we focused on reading literature that provides a broad overview of current and foundational research about teams beyond our specific context (e.g., Karzenbach and Smith 1993; Mannix and Neale 2005; Ilgen et al. 2005; Karlgaard and Malone 2015; Harrison and Klein 2007; Guzzo and Dickson 1996; Morgeson et al. 2009; Pentland 2014). We use our awareness of this literature to guide us towards a higher education-specific theory that can be connected to more general theories about how teams work. We also draw on existing literature to fill in gaps in what we have learned from the data we have collected so far.

\section{Data collection}

Our goal for data collection was to learn about the characteristics of a variety of team-based instructional change projects in undergraduate STEM. We examined award databases and solicited information from the higher education community to identify a broad list of projects that might involve such teams, as well as contact information for a lead person on each project. When searching award databases (via NSF, HHMI, and AAU websites), we started by finding abstracts that contained one or more of the keywords "team," "community," "collaborat", "committee," and "task force." We read these abstracts to select projects that seemed to be focused on improving undergraduate STEM instruction at a US institution and use an approach that centrally involves one or more teams (beyond the project leadership). When soliciting information from the community, we asked community members to identify projects that fit these same criteria. We explicitly defined "team" as "a group of people who are working to create a shared outcome," roughly based on Katzenbach and Smith's (1993) definition of a team. As above, this shared outcome was framed as being related to improving undergraduate STEM instruction within their institution. (Our research team informally considers shared outcomes to be things that are collectively developed by teams, such as shared curricular materials or pedagogical approaches. However, several project leaders interpreted "shared outcomes" to be broader in scope when asked to define it for their teams during interviews).

During the project identification phase, we asked potential participants to identify themselves or someone else as able to describe their work to us. We refer to these people as "project leaders" throughout this article. Because the size and scope of these team-based projects varied dramatically, project leaders' roles also varied. For example, some project leaders were members and leaders of their teams, while others were overseeing many teams.

We contacted a subset of the project leaders we identified to represent a variety of identification methods, institution types, single and multi-institution projects, project maturity, and funding sources (Table 1). We requested their participation in a 30-minute virtual, semistructured interview with the first author. Consistent with our above use of the term "project leader," we also noted that it would be possible to suggest a different project lead (or opt out). Twenty-eight project leaders were then interviewed, along with a small number of project co-leaders. The interviewer guided them to focus on four general topics: the nature of the team task, team structure and composition, resources and supports for teams, and how team members worked together. Specific questions included "Can you give a brief overview of the project and how it involves teams?", "What can you tell me about the structure of the team(s)?", "Are there any supports or resources available to make the work of the team(s) easier? If so, what are they?", and "How well do(es) the team(s) seem to be working together so far?"

We ended our data collection when we felt saturation was reached. While our search was framed to be broad, a majority of the teams in our dataset were focused on improving or creating courses. Because we could start to see both strong similarities and interesting differences among the teams that were focused on designing or redesigning courses, we chose to only analyze how teams enact this work. We did not include any teams that were not focused on course design or redesign in our sample. At a large scale, we noticed that project leaders described three general types of course change teams: interdisciplinary teams, teams initiated within single departments, and teams that were part of crosscampus, multi-team initiatives. There was also variety and similarity across these teams at a smaller scale, which was sufficient for us to conduct the analysis presented below. 
Table 1 Participant selection

\begin{tabular}{|c|c|c|c|}
\hline & Identified & Contacted & Interviewed \\
\hline \multicolumn{4}{|c|}{ Total number of projects } \\
\hline & 117 & 47 & 28 \\
\hline \multicolumn{4}{|c|}{ Identification method } \\
\hline Award database & 72 & 24 & 11 \\
\hline Community & 45 & 23 & 17 \\
\hline \multicolumn{4}{|l|}{ Institution type(s) } \\
\hline R1 & 59 & 13 & 11 \\
\hline R2/R3 & 27 & 13 & 7 \\
\hline Master's & 11 & 8 & 3 \\
\hline Baccalaureate & 7 & 6 & 3 \\
\hline Mixed/other & 13 & 7 & 4 \\
\hline \multicolumn{4}{|c|}{ Single or multiple institution(s) } \\
\hline Single & 88 & 37 & 20 \\
\hline Multiple & 29 & 10 & 8 \\
\hline \multicolumn{4}{|l|}{ Project maturity } \\
\hline Young ( $\leq 1$ year) & 34 & 14 & 9 \\
\hline Mature ( $\geq 1$ year) & 26 & 13 & 7 \\
\hline Nominally finished & 34 & 11 & 6 \\
\hline Unknown & 23 & 9 & 6 \\
\hline \multicolumn{4}{|c|}{ Primary funding source(s) } \\
\hline NSF-IUSE & 36 & 11 & 15 \\
\hline NSF-WIDER & 15 & 3 & 2 \\
\hline NSF-STEP & 16 & 5 & 2 \\
\hline NSF-RED & 8 & 5 & 1 \\
\hline Other NSF & 2 & 1 & 0 \\
\hline Helmsley/AAU & 6 & 3 & 2 \\
\hline $\mathrm{HHMI}$ & 11 & 4 & 2 \\
\hline Other external & 1 & 1 & 0 \\
\hline Internal & 9 & 4 & 4 \\
\hline Unknown & 25 & 12 & 9 \\
\hline
\end{tabular}

Number of representatives of potentially team-based instructional change projects who were identified, contacted, and interviewed, broken down to show project characteristics. We aimed to maximize the variety in each of these characteristics within our dataset. The information presented here reflects what was known during the selection process

\section{Analytical approach}

We pursued two overlapping analytical goals as part of the grounded theory methodology (Gibson and Hartman 2013). These goals, and the ways we pursued them, are consistent with the open coding and selective coding phases in grounded theory (Gibson and Hartman 2013). Our first goal was to identify categories of factors that project leaders might be able to leverage when setting up or supporting instructional change teams. The second was to refine these categories such that they can be meaningfully connected to a central category or problem.
Throughout our analysis, we wrote and iteratively refined memos about our interviews with project leaders. We started by examining transcripts about three projects that fit cleanly within the three main types of teams defined above. We initially coded for information related to the broad topics that we had used to design our interview protocol. We again focused on aspects of the team setup that project leaders can control. As categories began to emerge, we incorporated data from additional interviews and refined our categories accordingly.

During this process, we noticed that project leaders often proposed links between how teams are set up (our initial focus) and how teams work together and/or how teams think and feel about their work. We found ourselves frequently sorting aspects of the team setup into categories because they had similar links to these other two constructs. Following the logic and language of grounded theory, we began to treat these two constructs together as our core category, i.e., the category that embodies the central problem in the area being studied (Gibson and Hartman 2013). While refining our categories, we prioritized aspects of the team setup that could easily be related to this core category. (This aligns with our second goal and the method of selective coding.)

Because we also aim to end with a model of instructional change teams that shares basic features with a general model of teams, we also explicitly revisited the literature during the late stages of our analysis. The existing literature on teams resonated well with our emerging model and provides us with formal language to describe what we were finding.

First, the most basic model of teams links inputs to processes to outcomes chronologically. These "I-P-O" models are frequently used or adapted in the literature. Team inputs align with what we have thus far been calling "team setup" and generally include resources and other factors like team composition that are in place at the start of a team's work (Kozlowski and Ilgen 2006; Wageman et al. 2005; Guzzo and Dickson 1996). Researchers situate team processes as the central problem to consider when studying teams by both positioning it at the center of this model and explicitly discussing its importance (Ilgen et al. 2005; Guzzo and Dickson 1996; Morgeson et al. 2009; Marks et al. 2001; Mannix and Neale 2005). The construct of team processes aligns well with what we have been calling "how teams work together."

Second, researchers like Ilgen et al. (2005) and Marks et al. (2001) argue that not all links between inputs and outputs are active processes. As a solution to this shortcoming, Marks et al. (2001) propose a broader construct of mediators, which are then separated into team processes and emergent states. Marks et al. (2001) define team 
processes as "members' interdependent acts that convert inputs to outcomes through cognitive, verbal, and behavioral activities directed toward organizing taskwork to achieve collective goals," and emergent states as "the cognitive, motivational, and affective states of teams" ((Marks et al. 2001), p.357). They argue that team processes and emergent states cyclically influence each other while a team works together.

Marks et al. (2001)'s construct of mediators, broken up into team processes and emergent states, aligns well with what we identify as our core category. As noted above, we informally think of team processes as describing how teams coordinate their work together. Emergent states then describe the second key aspect of a team's work that we identified in our data, namely, what teams think and feel about their work. We adopted these constructs in our emerging model. With all of these pieces in place, we continued to incorporate data from additional interviews and refine our categories of team inputs until we reached saturation.

\section{Results}

Table 2 and Fig. 1 summarize our model of instructional change teams. The model includes five categories of team inputs as follows: the nature of the task, who participates, process constraints, external engagement, and access to resources. For clarity, each of these input categories is divided into two sub-categories. The team inputs are then linked to two mediator categories: team processes (how teams work together) and emergent states (how team members think and feel about their work). As discussed above, we show team processes and emergent states cyclically influencing each other based on what we know from prior research on teams.

For completeness, we also include four categories of team outcomes in our model: sustainability of the instructional changes, quality of the instructional changes, collaboration changes, and individual changes. We have not attempted to explore team outcomes empirically, but recognize that they are important. We include sustainability of the instructional changes as a category because it aligns with the outcomes often prioritized in the literature on organizational change (e.g., March (1991); Kezar (2014); Dee and Leisyte (2016)) and the goals of many instructional change projects (e.g., Chasteen et al. (2015); Matz and Jardeleza (2016); Corbo et al. (2016); Weaver et al. (2016); Elrod and Kezar (2017); Reinholz and Apkarian (2018)). The remaining three outcome categories are based on the literature about teams. The quality of the team product relative to the team's goals, changes in the capacity of team members to work together in the future, and changes in individual team members' knowledge, skills, or well-being are used to describe team outcomes in the literature (Wageman et al. 2005; Hackman 2011).
Table 2 Model components

\begin{tabular}{ll}
\hline Group/category/sub-category & $\begin{array}{l}\text { Brief description of the category } \\
\text { or sub-category }\end{array}$ \\
\hline
\end{tabular}

\section{Inputs}

Nature of the task

Team origin story

Prescribed task

How the team formed.

Whether or how the team's task is prescribed (who chooses the task).

Who participates

Team composition

Characteristics of team members, e.g., their expertise, interests, or authority.

Team boundaries

Extent to which team membership is well defined.

Process constraints

Prescribed process

Whether or how the team's process is prescribed by formal leaders, typically people outside the team.

Formalized roles

Whether or how team members' roles are clearly defined near the start of their work together.

External engagement

Opportunities to gather information

How team members gain useful information or expertise.

Opportunities to share information

How team members share their work with others.

Access to resources

Administrator support

Whether or how administrators try to help the team.

Rewards

How team members are rewarded for the work. Rewards can be tangible and/or symbolic.

\section{Mediators}

Team processes

How team members coordinate their work together.

Emergent states

What team members think and feel related to their work together.

\section{Outcomes}

Sustainability of changes

The sustainability of the instructional changes.

Quality of changes

The quality of instructional changes relative to the team's goals.

Collaboration changes

Changes in the capacity of team members to work together in the future.

Individual changes

Changes in individual team members' knowledge, skills, affect, or well-being.

Definitions for the categories (italic text) in our model. The first five categories are broken down into two sub-categories (regular text) each. These are the team inputs identified through our analysis. The two categories in the mediator group are adopted from (Marks et al. 2001) and align with our empirical findings. Three of the four categories in the outcome group (quality, ability to work together, individual outcomes) are based on Wageman \& Hackman (Wageman et al. 2005)'s dimensions of team outcomes. We also include sustainability as an outcome based on our empirical observations and the literature on organization change within and outside of higher education. We have not attempted to empirically explore mediators and outcomes in depth, but include them as important aspects of the model and placeholders for future research. See also Fig. 1 and the "Results" section of the main text 


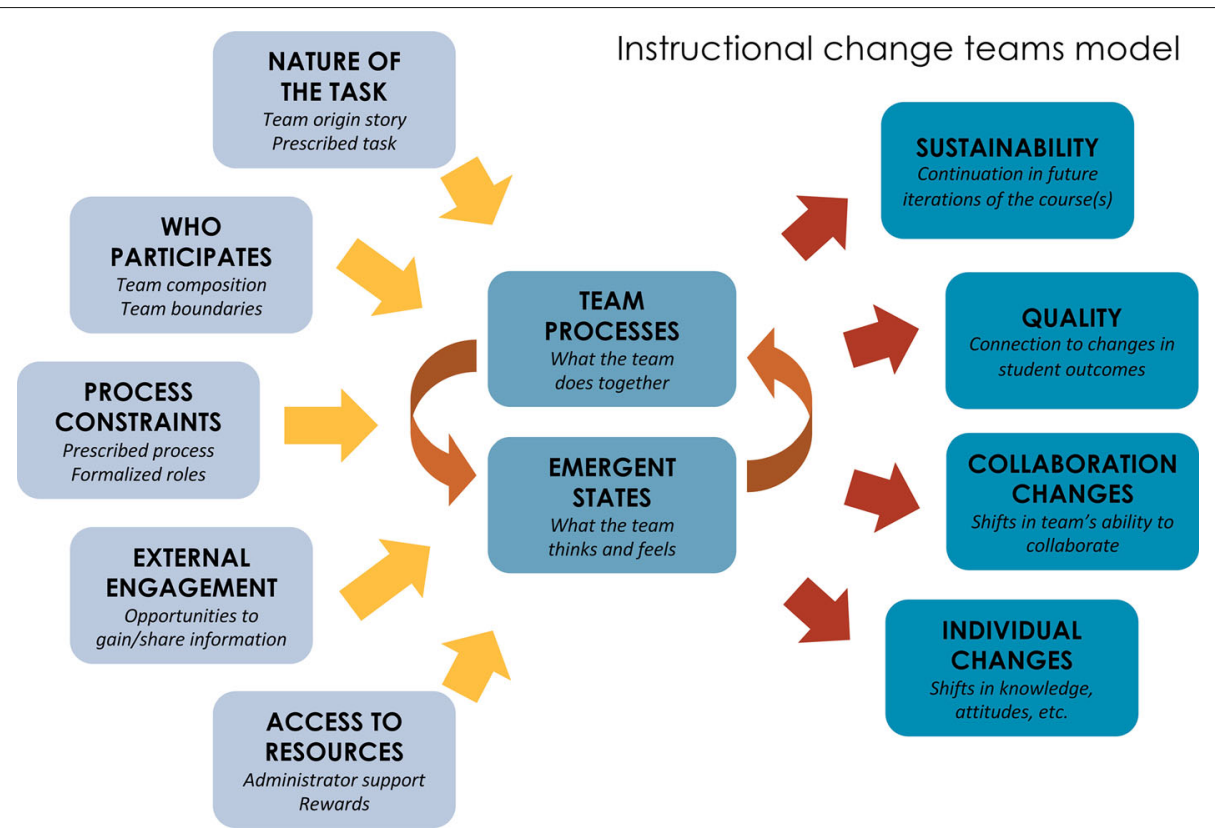

Fig. 1 Instructional change teams' model. A visual representation of our current model of instructional change teams, based on interviews with project leaders and existing literature. In this model, team inputs (purple, left) lead to mediators (light blue, center), and mediators lead to team outcomes (darker blue, right). The two categories of mediators, team processes and emergent states, are shown as cyclically influencing each other (Marks et al. 2001). See also Table 2 and the "Results" section of the main text

In the remainder of this section, we define and describe each category of team input based on what we learned from project leaders. Where possible, we justify the categories by highlighting project leaders' hypotheses about how they are linked to team processes and/or emergent states. This analysis is intended to be descriptive, rather than evaluative. We consider some possible implications of differences across teams by drawing connections to existing literature in the "Discussion" section.

\section{Nature of the task \\ Team origin story}

This category describes how teams form. This includes aspects such as what catalyzed the team's formation, how quickly team members organized themselves around their task, and how quickly teams began to enact the instructional changes they were developing. The three examples below illustrate the range of formation stories in our dataset. Most teams share characteristics with one or more of these examples.

First, some teams form when an administrator asks the team to work on a certain task, within a certain time period, and invites people to join. This quote illustrates such a team:

So the team had to be composed of an administrator and a variety of faculty. It couldn't just be instructional faculty. That team that formed was invented, it was created. That was the team that attended [a workshop for PULSE, an undergraduate biology education-focused initiative], and then when we came home, my associate chair...led the team...we call 'the PULSE home team.'

These teams have clear start dates. We observe that their work often involves a significant amount of planning and visioning and is less focused on quick implementation of instructional changes.

Second, some teams form slowly and "organically," without a push from an external entity. Teams like this decide to start meeting because they notice a problem with instruction in their department. They spend a long time growing their membership and planning out what changes to make before enacting them. One project leader describes their departmental team formation in this way:

It has been a long journey, you know what I mean? [T]his wasn't something we came up with this summer, and we said, 'We're gonna implement 'Vision and Change," or, 'We're gonna do active learning.' It's been an ongoing cultural change, I would say all the way back to probably [5 or 6 years ago]. It just took a few years to start getting people on board.

Leaders of similarly formed teams provide similar descriptions of the pace of the team's work, stating that it lacks a 
"sharp start" and describing the project as a "slow march towards a goal."

Finally, some teams form in response to a local, small-scale funding opportunity housed within their institution. One project leader describes such a model:

[Our project] was designed around the idea of we want to renovate and innovate the large lecture courses in a particular college]. The Dean created this, essentially what was an internal grant program. Basically like come here, tell us what courses you want to fix, why those courses are strategic to be fixed.

Such teams tend to form quickly because they are striving to meet an internal funding deadline. Within our dataset, these project leaders often require teams to develop a plan upfront for what the changes will be and/or how the work will be done. There also tends to be an expectation that the team will begin to enact instructional changes soon after they form.

\section{Prescribed task}

This category captures whether or how the team's task is prescribed. A fully prescribed task is one where someone outside of the team dictates what the team will produce together.

Unsurprisingly, teams with highly prescribed tasks also have high accountability to other people. A typical team in this situation would be asked to complete their task by an administrator, as described in the first origin story above. One project leader describes a team in this situation:

[The team leader] is very strongly beholden to the curriculum. He's designing a lower division lab, and it has to fit in with the existing lecture, and prepare students for the next course, and he's had significant involvement from both faculty in [his] department, and faculty across other departments for whom this serves as a service course. I'd say [the team has] like, not quite zero autonomy.

Other project leaders describe a similar lack of autonomy and strong oversight from other entities, such as a sense that "people [in the institution] are looking at us."

Other teams have tasks that are loosely prescribed. Here, the project leader provides strong guidance about what instructional changes to pursue, but they are also members of the team. Thus, there is little or no external accountability for the team to follow the prescribed task. These teams tend to have formed slowly, as in the second origin story above. Based on our dataset, these project leader often do work before the team forms to determine what changes could be beneficial to students. They often focus on motivating team members to teach specific knowledge and/or skills to students. They may also create or promote opportunities for individual team members to learn about pedagogy.

Finally, some project leaders support teams in pursuing highly emergent tasks. This is particularly evident on teams that are part of multi-team projects. Project leaders may highlight specific pedagogical strategies by leading and/or encouraging attendance at training events. They may require teams to go through a proposal stage initially and ask them to agree to incorporate formative feedback at that time. However, these teams ultimately have significant choice in what tasks they pursue together.

\section{Who participates \\ Team composition}

This category captures the characteristics of team members. Each project leader describes one or more kinds of team member characteristics as important for how teams work together: (a) team members' expertise, (b) their interests and viewpoints, and (c) their influence over particular courses.

Project leaders tend to talk about team members' expertise when they feel that the team would not have the necessary expertise to do the work without particular kinds of people. For example, one project leader recalls that before they hired an education research specialist, their team was struggling to make progress towards their goals:

\section{[The education specialist on the team] started in [a particular year], and certainly is the person tasked with helping to lead this charge in the implementation and assessment phase, but there has been a team and there has been, I think, positive movement [before then]. It's just that we really didn't have the expertise we needed at the table to effectively implement that change, and so that was kinda one of the first steps of our change movement, was to allocate resources, people, to help us to do this properly and to do it with research-based practices and true assessment along the way.}

This project leader's statement suggests that "hav[ing] the expertise we needed at the table" was important for shaping the team's process. Team members who have specific expertise are not always brought in to fill specific, formalized roles, as is the case here. But the concept of bringing in people with relevant expertise to make the task more possible comes up frequently.

Project leaders universally discuss how team members must have some interest in the work in order to engage in it. This usually refers to team members' desire to improve their own instruction and/or to collaborate with local colleagues. However, team members can also be interested in the work because they want to shape the team's task in ways that represent their views and the views of 
their colleagues. For interdisciplinary tasks, team members often want to represent the views of their disciplines. Team members may also simply have different priorities than their colleagues, despite having similar disciplinary training.

Lastly, team composition can be driven by faculty's influence over specific courses. Even in these cases, willingness to participate is seen as critical. However, team members likely feel more compelled to participate when the team's task is shaping a course that they have been assigned to teach than if the task was not aimed at specific courses. As a result, teams that target particular courses can represent a broader set of interests and motivations relative to teams that flexibly work on whatever courses are available to them.

\section{Team boundaries}

This category captures the extent to which team membership is well defined. Most teams have fixed team boundaries: at any given time, it is clear who is on the team and who is not. Project leaders tend to view this as normal and do not elaborate on the reasoning behind this team setup. But a significant number of teams have what we call "fuzzy" boundaries. In these cases, some people are clearly part of the team and others may or may not be, depending on how team membership is defined.

One project leader describes their fuzzy boundaries model of team membership as a "core with a few satellites." Others describe how people within the institution are invited to "drop in" to observe the team's work or to participate only in certain aspects of the work. One project leader elaborates below:

We've had four instructors and a head TA really deeply involved in the change, and last semester, as we were planning this change, we probably had around ten people involved. But then the real nitty gritty, you know, 'What are we gonna do on day ten?', that group got narrowed down.

This project leader also explains how they leverage a flexible participation model to invite new instructors into the team's work:

We already know that there's a new instructor coming on board next semester, cause I won't be teaching anymore. So we've already asked him to start coming to our meetings so he can really know what's going on and have a say, also, in what's gonna happen.

Consistent with this logic, several project leaders describe how encouraging stakeholders to be peripherally involved via fuzzy boundaries can allow a team to consider ideas that will help the work to be sustainable.

While most project leaders who describe fuzzy boundaries advocate for their utility, some project leaders describe fuzzy boundaries as a negative aspect of their teams. For example, one project leader notes that fuzzy boundaries were tied to team members gradually participating less and less in team activities. In other words, fuzzy team boundaries can be a pathway to attrition.

\section{Process constraints \\ Prescribed process}

This category captures if and how project leaders specify process expectations to teams. We notice a fairly strong division in whether or not project leaders describe process expectations based on the overall team type. When project leaders are part of their teams (e.g., on single-team projects), they often describe taking a leadership role in the team's work, but it is unclear if/when their ideas about how the team should work together are made explicit to team members. In contrast, multiple project leaders in our dataset who are not part of their teams (e.g., on multiteam projects) recount a set of process expectations that are made explicit to team members upfront.

The following quote illustrates what a prescribed process can look like and the possible influence on team processes:

We gave them a template of 'What do you want? What is your goal for the meeting? What is it you want to have as an outcome of this? Who's going to take notes?' and 'blah blah blah,' and do some reflection at the end. They were often around these student-centered learning activities that they co-developed during the summer institutes. [We tried to] have them use kinda common agendas when they came together. And that worked some, but not great, because faculty tend to like to do whatever they want to do. But as long as they were making progress towards goals and they could have a clearly articulated way of explaining the work they're doing ..., then we were pretty fine with kind of leaving them to do that.

Here, we see that these project leaders provide specific guiding questions that encourage teams to set short- and long-term goals and to focus on developing and revising curricular materials using learning progressions. This project leader notes that the teams do not necessarily follow this process guidance exactly as prescribed, but that providing the guidance does influence how the teams work together in some way.

We see a similar philosophy about prescribing a team process reflected in many of the other multi-team projects. This is particularly true for mature projects, which could indicate that multi-team projects that start out with an emergent approach to team processes tend to shift towards a more prescribed process over time. One project leader explicitly describes such a shift. In the 
quote below, they recall how they started with almost no process guidance-with unsatisfactory results - and ended with something similar to what was described above:

Through that first year one of the things that we learned was that [very limited guidance] was not nearly enough structure. We started instituting different evaluation procedures and screening procedures [in the second and third year] to really check to see is this three faculty in name only, or is this three faculty who are actually working together in trying to create a shared understanding of what these courses are about? So that we've basically said, we're prioritizing and valuing teams of faculty that are working together that show common commitment and purpose. We try to keep [their processes] the same. So it's the meeting weekly. Discussing teaching and having some consensus building about what is best practices. Collecting evidence. Striving for the same student outcomes. Figuring out ways to make their teaching sustainable beyond themselves. In the third year, we started screening teams based on how they were performing, according to that.

The specifics of what processes are prescribed here are slightly different from what the first project leader illustrated. But in both cases, we see common elements such as encouraging teams to articulate shared goals and encouraging uniformity in team processes across a multi-team project.

\section{Formalized roles}

This category encompasses whether and how team members have formalized, prescribed roles from the start of their work together. We find that it is relatively uncommon for teams to have no formalized roles to start out. When this does happen, it is generally the case that most or all team members are faculty who are teaching courses that are the focus of the team's work. Sometimes distinct roles never develop on these teams, but our data suggest that team leaders often emerge later on in these cases.

Team members who would not otherwise be highly involved in the teaching of the focal courses, such as education specialists, administrators, and some students, tend to have different roles than other team members. Educational specialists sometimes have leadership roles (e.g., defining meeting agendas, collecting information from stakeholders, securing support for the team, etc.) or more peripheral, advisory roles. Administrators may have the role of approving substantial curricular changes while participating less in day-to-day work. Students may have roles such as collecting and synthesizing data about course outcomes or supporting a lead instructor in pursuing specific sub-tasks (e.g., creating specific materials).
One project leader elaborates on what these roles are on their team:

[Y]ou need someone that will work behind the scenes. [The] one hour and a half that people are meeting is just the culmination of what we did for so long to come up with this one hour and a half that would be really, really effective. We are...collecting data [from students] to show the faculty members, writing [and] sending surveys to students, manipulating the data in a way that the faculty member[s] can see and... analyze.

The project leader argues here that having someone whose role is to collect and synthesize student data outside of team meetings is important for helping other team members to engage in productive course change work. While the project leadership is responsible for carrying out all of this data collection and analysis on this team, we see students filling similar roles on other teams.

All of the above roles relate to who is responsible for carrying out specific sub-tasks that can help the team. The other prominent reason that team members have formalized roles is related to their control over the focal courses. The project leaders we interviewed often assume that instructors who are teaching the focal courses have more decision-making power than other team members. They almost always describe course instructors, particularly faculty, as having significant autonomy in their classrooms. They consistently state that faculty will take these heightened decision-making roles regardless of what else project leaders may want to do. Therefore, like other formalized roles, a special role for instructors may be commonly recognized among the team before they start their work together.

\section{External engagement \\ Opportunities to gather information}

This category describes whether or how teams gain new information or expertise for their work.

Many project leaders describe how team members gather information that can improve the quality of team outcomes. For example, individual team members sometimes take up opportunities to attend teaching workshops and learn about pedagogy. One project includes team mentors who are specifically tasked with interacting with mentors of other teams to bring useful information back to their own team. Workshops and summer institutes can also provide opportunities for team members to learn about new pedagogical approaches and productive team processes as a team. Joint participation in workshops and institutes can increase the information that the team holds collectively, as well as the amount of information that is shared among team members. 
Some teams also have specific times when they gather information from stakeholders. Several project leaders describe full-day departmental retreats such as this one:

We had a one day retreat, almost exactly a year ago, [with] everybody that had any interest in this project. We got everybody in the same place for a whole day and we fed them and we talked about what kind of changes we all wanted to see.

Retreats like this tend to be more common for single teams than for teams within larger, multi-team projects.

\section{Opportunities to share information}

This category describes whether or how team members share information with others.

The activities that allow teams to share information often have multiple purposes and thus overlap with other categories, specifically opportunities to gather information and rewards. One project leader describes how the "show and tell" meetings that their team has can serve all three purposes (sharing information, gathering information, and feeling rewarded):

We have in the small meetings and short meetings every other week, ten minutes or sometimes more, show and tell, that every time another faculty member shares something great that they are doing in their classroom, [an] innovation or something. They learn from each other, but also get [a] place to brag about this, and so I think they benefit.

Here, the project leader emphasizes that the act of sharing can benefit team members, perhaps by helping them to feel good about their work or helping them to recognize their own progress. Poster sessions and other similar gatherings are described similarly by other project leaders.

Teams may also share information with stakeholders. This can keep stakeholders informed about what the team is doing. For example, teams may report out at department meetings, as described here:

It's really nice when [our team's] activities are on the agenda [at faculty meetings], and that's an opportunity to catch people up, and they know who the people are they can come to. And we can give them a heads-up about whatever activities we might be turning to them for.

This team uses department meetings to bring other people along with the work the team is doing, to invite informal interactions, and to gain traction for recruiting people to participate in structured activities related to the team's work.

\section{Access to resources}

\section{Administrator support}

This category describes whether and how administrators try to help teams. Within our dataset, almost all project leaders describe some form of administrator support. We consider administrator support to encompass both internal funding (present on some but not all projects) and other types of support.

For one, administrators (typically department chairs) may provide assurance that teams will have a say in which instructors will be assigned to the courses they are focused on improving. Within our dataset, it is also relatively common for administrators to provide access to financial resources. For example, administrators sometimes provide internal funding that helps project leaders to secure external funding, such as seed funding or matching grants. They sometimes provide monetary rewards to project leaders and/or team members. The project leaders we interviewed often described financial resources from administrators as sending a message that administrators value the team's work.

Some project leaders suggest that administrators can demonstrate support and help teams make progress by actively participating in teams. For example, one leader of a multi-team project observes the following:

In [certain teams] we had chairs... who actively came to all the summer institutes, participated in workshops, tried these things out in their own classrooms, et cetera. But they didn't take a leadership role. One of our observations is that teams that have chairs that are actively involved tend to make better, more expansive progress in what they're doing. I think it's because there's an incredibly strong message there that, 'This is where we're going. This is what we're going to be doing. And I as your Chair support this work.'

Other project leaders suggest that administrators can help teams by encouraging them from a distance. For example, one project leader argues that distant messages of support from administrators provides teams with a sense of safety and gives them freedom to pursue the task in the ways that they want:

The Provost's Office was supportive. Like, 'This is a great idea,' and, 'You should do it.' Some of the faculty members ... were pre-tenure, so there was a definite statement from the Provost's Office that, 'If this goes badly, we're not gonna hold it against anyone,' kind of thing. 'This isn't gonna be, we're not gonna use an observation of [the course changes] to decide whether you should get tenure or not.' They were supportive in that way, but, mostly, they were just ... you know ... give us the liberty to do what we wanted.

We note that while the teams on this project were interdisciplinary and not housed in a specific department, some department-level teams report similar levels of involvement from department chairs. Other project leaders who 
follow this model describe how administrators let things "trickle up" and act as "cheerlead[ers]," often in coordination with providing tangible resources.

\section{Rewards}

This category describes how team members are rewarded for their work. Project leaders describe several different kinds of rewards. Almost all of these rewards (stipends, salary, course buyouts, food, titles, newsletters, showcases, etc.) are intended to increase team affect. Monetary rewards (stipends, salary, course buyouts) also serve the purpose of freeing up team members' time to do the work. Sometimes they are given to individual team members so that they can do more intensive work. In these cases, particularly when the paid team members are students, funding may be seen as a necessary condition for participation on the team. In other cases, rewards with monetary value are distributed to all team members. These rewards are intended to increase how much time the whole team spends together.

Some project leaders describe institutionalized rewards as important factors in their decisions about what special rewards to provide. One project leader explains how strong built-in rewards for high-quality teaching lessened the need to provide additional monetary support to team members:

\section{There [were] modest stipends that were paid through [grant funding], like on the order of five hundred dollars, if you make a commitment to do these things that's kind of like a week's worth of work. It wasn't a high level. Other than that, it was really just a mutual commitment of the folks that were involved... We expect faculty members to be productive scholars, but our number one evaluation of faculty members is as high quality teachers and mentors to our students. That is just part of the institutional culture.}

While this institutional reward structure seems exemplary for supporting instructional change, others also describe integrating rewards for team members with existing departmental or institutional expectations. For example, some leaders have participation count as service or write letters of support for junior faculty's promotion and tenure portfolios. Some project leaders exclusively capitalize on existing reward structures with the intent of promoting a shift in what is seen as expected in the long term.

\section{Discussion}

We identified five categories of team inputs that project leaders describe as consequential for how teams work together: the nature of the task, who participates, process constraints, external engagement, and access to resources. These categories represent key decisions that project leaders make when setting up or supporting instructional change teams. Articulating this set of inputs for instructional change teams represents a new contribution to the literature. At the same time, we see multiple similarities to existing literature on teams in other contexts and organizational change in higher education within these categories.

Looking across our data, we notice that all project leaders seem to view some supports as beneficial to teams. These views are corroborated by existing literature. For example, all project leaders seem to agree that pedagogical training as external engagement for team members (via workshops, summer institutes, guidance from education specialists, etc.) is beneficial. Even though such training is occasionally limited or absent, project leaders never indicate that it would be unhelpful. This aligns strongly with long-standing ideas from the literature on instructional change (e.g., Ball and Cohen 1999; Bouwma-Gearhart et al. 2014; Manduca et al. 2017).

Similarly, project leaders seem to agree that engagement with new ideas (e.g., through interactions with other teams, or through the training mentioned above) and messages of support from organizational leaders can help teams. Both of these broader ideas align with literature about teams in other contexts (Edmondson 1999; Pentland 2014; Katzenbach and Smith 1993; Wageman et al. 2005; Ilgen et al. 2005; Hackman 2011). For example, Pentland (2014) argues that the most effective teams frequently explore their social networks to find new ideas, while Edmondson (1999) argues that support from organizational leaders can enable teams to experience "psychological safety" and thus engage in productive risk-taking.

We also notice considerable variations in how teams are set up. In particular, project leaders vary in whether or not they encourage administrators to directly participate on teams; recruit instructors to participate because they teach specific, pre-determined courses; create fixed boundaries for team membership; and try to prescribe the team's task. We propose several, complementary explanations for why this might be the case.

First, we suggest that although project leaders ultimately make different choices about how to support teams, they would agree about what at least some team processes and emergent states would look like in an ideal case. We see evidence of what some points of agreement might be in our data, which are again corroborated by existing literature on teams. The literature on teams suggests that healthy team processes include meeting often (Katzenbach and Smith 1993; Pentland 2014; Karlgaard and Malone 2015), sharing ideas freely (Wittenbaum and Stasser 1996; Edmondson 1999; Bunderson and Sutcliffe 2002; Keltner et al. 2003), enacting and reflecting on 
changes (Edmondson 1999; Marks et al. 2001), and following through on commitments to each other (Pentland 2014; Katzenbach and Smith 1993). Similarly, the literature on teams suggests that healthy emergent states include shared values around and commitment to the task (Jehn et al. 1999; Pentland 2014; Katzenbach and Smith 1993; O'Reilly III et al. 1989; Lau and Murnighan 1998; Harrison and Klein 2007), a sense of joint ownership over the task (Pentland 2014; Katzenbach and Smith 1993), and a sense that the team can achieve their goals (Wageman et al. 2005; Karlgaard and Malone 2015; Ilgen et al. 2005; Hackman 2011). We see evidence that at least some project leaders consider these to be favorable processes and emergent states and do not see any evidence to suggest that other project leaders would consider these to be unfavorable.

While each of the above team processes and emergent states may indeed contribute to positive team outcomes, it can be difficult to set up instructional change teams that are well positioned to embody all of them at once. Thus, our first proposed explanation for the variations we see in our data is that conflicting project leader decisions represent different compromises project leaders make when deciding how to help teams think, feel, and interact in ways that lead to positive outcomes.

To explore this idea, we can use our data to speculate about what project leaders' priorities could be. One motivator for project leaders could be to help teams to both feel that they can achieve their goals and ultimately do so. Many teams aim to create lasting change within their departments or institutions. Many stakeholders within the institution (future instructors of the focal course, instructors who teach related courses, administrators, etc.) can shape the extent to which this goal will be achieved. Project leaders who prioritize team efficacy and the sustainability of the team's work may be more likely to recruit department chairs or other administrators to act as members of teams, ask team members to participate because they have control over specific courses at that time, and/or encourage stakeholders such as future course instructors to peripherally participate in the team.

While the decisions above may help teams to achieve lasting instructional change and feel confident that they are making progress towards this goal, the alternative decisions also have affordances. Instructors may feel more free to share risky ideas such as relevant challenges they are facing in the classroom if their department chair is not an active member of the team. Team members may be more likely to start with strong, shared values and commitment to the task if participation in the team is completely voluntary. Similarly, it may be easier for team members to build shared values around the team task over time if the team has clear, fixed boundaries.
The existing literature on teams does not represent these tensions well. Instead, researchers who study teams in other contexts provide recommendations that lean towards the second set of choices we describe: that leaders should strive to minimize power differentials on teams (Keltner et al. 2003; Harrison and Klein 2007), ensure that team members share the same values for the task (Jehn et al. 1999; Pentland 2014; Katzenbach and Smith 1993; O'Reilly III et al. 1989; Lau and Murnighan 1998; Harrison and Klein 2007), and establish clear team boundaries (Wageman et al. 2005; Hackman 2011). The logic we describe above reflects the logic behind these recommendations. But we think that uncritically following the teams literature here would provide a false sense of certainty. In the context of higher education instructional change, it is important to think about how to involve many people in the change process because, as stated above, many people are stakeholders who can strongly shape the lasting outcomes of a team's work. This echoes our original argument for why it is important to pursue context-specific research on higher education teams.

With this point in mind, we return to our earlier question of why project leaders seem to disagree about how to set up teams. The notion that higher education has distinctive features, along with the apparent disagreement around how much a team task should be prescribed, provides additional insight into what might be happening here. The high degree of autonomy that team members (particularly instructors) tend to expect distinguishes higher education from other organizational contexts (Kezar 2001). Thus, the extent to which an instructional change team's task can be prescribed and result in an effective team cannot be answered by looking at the existing literature on teams in other contexts.

This suggests at least two other viable explanations for why project leaders support teams differently. One is that there are multiple team setups that can be equally successful. Different project leaders might be advocating for different, optimal team setups. In the example above, perhaps it is possible for project leaders to set up highly effective teams by asking them to pursue a prescribed task if the team setup also includes significant, tangible support from administrators and education specialists (but not otherwise).

Lastly, it is possible that project leaders simply do not know what team setup is optimal for their situation. Project leaders may have a limited or biased view of how well teams are working together. They may still be experimenting with how to best support their teams, particularly on projects that are relatively young. Local constraints may prohibit project leaders from being able to test out supports that they think might help teams. More broadly, it would be impossible for local change agents to test all 
potentially effective team setups as a way to fully optimize how teams at their institution work together.

The organizational change literature provides a final piece of insight that supports this last explanation. March (1991) argues that it can be costly for organizations to experiment too much. It takes time for members of an organization to adjust to and refine changes so that they work well for them. As a result, leaders tend not to find the optimal setup for their organization (March 1991). Applying this idea to team-based instructional change projects, many project leaders may have identified team setups that work well for them, but are not quite optimal. If this explanation is accurate, it suggests that if we want to find the best ways to set up instructional change teams, we need to continue to look across multiple teams and institutions.

\section{Conclusions}

The preliminary model that we present here represents progress towards practical and research goals. On the practical side, this research begins to provide guidance to change leaders who aim to support instructional change teams. We intentionally use the term "change leaders" here to emphasize that many people can take on leadership roles in helping to promote effective change within their institutions. Change leaders can use our model to identify key decisions that need to be made when working to set up new teams or create new supports for existing teams. Our model can also support change leaders in developing hypotheses about how and why their decisions will be consequential for team outcomes. Such hypotheses can help change leaders to make promising decisions initially and to productively refine what supports they provide if they notice challenges or limitations along the way.

From a research perspective, our model is meant to serve as a stepping stone towards understanding instructional change teams. Some aspects of how to set up instructional change teams to be successful are already well established and supported by the literature. But our data show that there is not a clear consensus on how to set up teams overall. We see variation in many of the decisions that project leaders make, as well as how they justify these decisions.

We also find that some distinctive aspects of higher education-the large number of stakeholders who can help or hinder the sustained impact of instructional change work and the strong expectations of instructor autonomy-can make it difficult to create highly effective teams. This suggests that while it can be fruitful to draw on existing literature about teams in other contexts, it is important to pursue additional, contextualized research on instructional change teams. Extrapolating further, these distinctive aspects of higher education could also be at play for teams that are focused on different goals, such as increasing equity and inclusion in their departments more broadly. Only context-specific research can fully allow researchers to understand what does (and does not) tend to lead to effective teams. Our research on instructional change teams brings us closer to understanding a variety of higher education teams, but more work would be needed to understand how higher education teams pursue these other goals.

One way that future work could productively challenge or expand on our initial model of instructional change teams would be to seek the perspectives of team members. We exclusively interviewed project leaders in order to gain an overview of a wide range of teams. Knowledge of team members' perspectives is likely needed to advance our understanding of what an ideal team setup might be within a particular context. Future research could explore team members' perspectives on what aspects of how teams are set up are salient to them. Future research could also draw on team members' perspectives to identify and analyze key dimensions of team processes and emergent states that emerge from various team setups, or observe team interactions with this in mind. On a different level, future work could also adapt our model to represent how higher education teams pursue complementary or alternative goals. All of this research could further support change leaders in promoting improvements to undergraduate STEM instruction.

\section{Acknowledgements \\ This work was supported by the National Science Foundation under grant \#1525393. Any opinions, findings, conclusions, or recommendations expressed in this material are those of the authors and do not necessarily reflect the views of the National Science Foundation. We are grateful to the project leaders who agreed to be interviewed for this study and to everyone who gave us feedback as we developed this model.}

\section{Availability of data and materials}

The data that support the findings of this study are available on request from the corresponding author $\mathrm{AO}$. The data are not publicly available due to them containing information that could compromise research participant and/or team member privacy.

\section{Author's contributions \\ The authors collaboratively developed and refined the model of instructional change teams, as well as the overall study design. AO took primary responsibility for the data collection, data analysis, and writing. The remaining authors participated in assisting with the data analysis, and read, edited, and approved this manuscript. All authors agree to be accountable for all aspects of the work in ensuring that questions related to the accuracy or integrity of any part of it are appropriately investigated and resolved. All authors read and approved the final manuscript.}

\section{Ethics approval and consent to participate}

The Human Subjects Institutional Review Board at Western Michigan University determined that the procedures in this study did not require their approval.

\section{Competing interests}

The authors declare that they have no competing interests.

\section{Publisher's Note}

Springer Nature remains neutral with regard to jurisdictional claims in published maps and institutional affiliations. 


\section{Author details}

${ }^{1}$ Department of Physics, Texas State University, 601 University Drive, San Marcos, 78666, USA. ${ }^{2}$ Center for Research on Instructional Change in Postsecondary Education, Western Michigan University, 1903 W. Michigan Ave., Kalamazoo, 49008, USA.

Received: 17 October 2018 Accepted: 28 April 2019

Published online: 19 June 2019

\section{References}

Austin, A.E. (2011). Promoting evidence-based change in undergraduate science education. Fourth Committee Meeting on Status Contributions and Future Directions of Discipline-Based Education Research, 1-25.

Ball, D., \& Cohen, D. (1999). Developing practice, developing practitioners: Toward a practice-based theory of professional education, In Teaching as the learning profession: Handbook of policy and practice. https://doi.org/10. 1037/0022-3514.90.4.644 (pp. 3-32). San Francisco: Jossey-Bass.

Bouwma-Gearhart, J., Perry, K.H., Presley, J.B. (2014). Improving postsecondary STEM education: Strategies for successful interdisciplinary collaborations and brokering engagement with education research and theory. Journal of College Science Teaching, 44(1), 40-47.

Bunderson, J.S., \& Sutcliffe, K.M. (2002). Comparing alternative conceptualizations of functional diversity in management teams: Process and performance effects. Academy of Management Journal, 45(5), 875-893.

Chasteen, S.V., Wilcox, B., Caballero, M.D., Perkins, K.K., Pollock, S.J., Wieman, C.E. (2015). Educational transformation in upper-division physics: The science education initiative model, outcomes, and lessons learned. Physical Review Special Topics-Physics Education Research, 11(2), 20110.

Corbo, J.C., Reinholz, D.L., Dancy, M.H., Deetz, S., Finkelstein, N. (2016). A framework for transforming departmental culture to support educational innovation. Physical Review - Physics Education Research, 12(1), 010113. http://arxiv.org/abs/1412.3034.

Dee, J.R., \& Leisytè, L. (2016). Organizational learning in higher education institutions: Theories, frameworks, and a potential research agenda. In M.B. Pauslen (Ed.), Higher Education: Handbook of Theory and Research, chap. 6 (pp. 275-348). Switzerland: Springer International Publishing.

Edmondson, A. (1999). Psychological safety and learning behavior in work teams. Administrative Science Quarterly, 44(2), 350. https://doi.org/10.2307/ 2666999 http://www.jstor.org/stable/2666999?.origin=crossref.

Elrod, S., \& Kezar, A. (2017). Increasing student success in STEM: Summary of a guide to systemic institutional change. Change: The Magazine of Higher Learning, 49(4), 26-34. https://doi.org/10.1080/00091383.2017.1357097 https://www.tandfonline.com/doi/full/10.1080/00.

Gast, I., Schildkamp, K., Veen, J.T.V.D. (2017). Team-based professional development interventions in higher education : A systematic review. Review of Educational Research Month 201X, 87(4), 736-767. https://doi.org/ 10.3102/0034654317704306 http://journals.sagepub.com/doi/pdf/10. 3102/0034654317704306.

Gehrke, S., \& Kezar, A. (2017). The roles of STEM faculty communities of practice in institutional and departmental reform in higher education. American Educational Research Journal, 54(5), 803-833. https://doi.org/10.3102/ 0002831217706736 http://journals.sagepub.com/doi/10.3102/ 0002831217706736 .

Gibson, B., \& Hartman, J. (2013). Rediscovering grounded theory. Thousand Oaks: Sage.

Glaser, B.G., \& Strauss, A.L. (2017). Discovery of grounded theory: Strategies for qualitative research. New York: Routledge.

Guzzo, R.A., \& Dickson, M.W. (1996). Teams in organizations: Recent research on performance and effectiveness. Annual review of psychology, 47(1), 307-338.

Hackman, J.R. (2011). Collaborative intelligence: Using teams to solve hard problems. Oakland: Berrett-Koehler Publishers.

Harrison, D., \& Klein, K.J. (2007). What's the difference?Diversity constructs as separation, variety, or disparity in organizations. Academy of Management Review, 32(4), 1199-1228. https://doi.org/10.5465/AMR.2007.26586096.

Henderson, C., Beach, A., Finkelstein, N. (2011). Facilitating change in undergraduate STEM instructional practices: An analytic review of the literature. Journal of Research in Science Teaching, 48(8), 952-984. https:// doi.org/10.1002/tea.20439 http://doi.wiley.com/10.1002/tea.20439.

Ilgen, D.R., Hollenbeck, J.R., Johnson, M., Jundt, D. (2005). Teams in organizations: From input-process-output models to IMOI models. Annual
Review of Psychology, 56(1), 517-543. https://doi.org/10.1146/annurev. psych.56.091103.070250 http://www.annualreviews.org/doi/10.1146/ annurev.psych.56.091.

Jehn, K.A., Northcraft, G.B., Neale, M.A. (1999). Why differences make a difference: A field study of diversity, conflict, and performance in workgroups. Administrative Science Quarterly, 44(4), 741. https://doi.org/10. 2307/2667054 http://www.jstor.org/stable/2667054?origin=crossref.

Karlgaard, R., \& Malone, M.S. (2015). Team genius: The new science of high-performing teams. New York: HarperCollins.

Katzenbach, J.R., \& Smith, D.K. (1993). The discipline of teams. Harvard Business Review, 71(2), 111-120.

Keltner, D., Gruenfeld, D.H., Anderson, C. (2003). Power, approach, and inhibition. Psychological Review, 110(2), 265-284. https://doi.org/10.1037/ 0033-295X.110.2.265 http://doi.apa.org/getdoi.cfm?doi10.1037/0033295X.110.2.265.

Kezar, A. (2001). Understanding and facilitating organizational change in the 21st century. San Francisco: Jossey-Bass.

Kezar, A. (2014). How colleges change: Understanding, leading, and enacting change. New York: Routledge.

Kozlowski, S.W.J., \& Ilgen, D.R. (2006). Enhancing the effectiveness of work groups and teams. Psychological Science in the Public Interest, 7(3), 77-124.

Lau, D.C., \& Murnighan, J.K. (1998). Demographic diversity and faultlines: The compositional dynamics of organizational groups. Academy of Management Review, 23(2), 325-340. https://doi.org/10.2307/259377.

Manduca, C.A., Iverson, E.R., Luxenberg, M., Macdonald, R.H., McConnell, D.A., Mogk, D.W., Tewksbury, B.J. (2017). Improving undergraduate STEM education: The efficacy of discipline-based professional development. Sci. Adv., 3(2), 1-16.

Mannix, E., \& Neale, M.A. (2005). What differences make a difference? Psychological Science in the Public Interest, 6(2), 31-55. https://doi.org/10. 1017/S096318019870101X.

Manogue, C.A., Siemens, P.J., Tate, J., Browne, K., Niess, M.L., Wolfer, A.J. (2001). Paradigms in physics: A new upper-division curriculum. American Journal of Physics, 69(9), 978-990.

Marbach-Ad, G., Briken, V., Frauwirth, K., Gao, L.Y., Hutcheson, S.W., Joseph, S.W., Mosser, D., Parent, B., Shields, P., Song, W., Stein, D.C., Swanson, K., Thompson, K.V., Yuan, R., Smith, A.C., Gentile, J. (2007). A faculty team works to create content linkages among various courses to increase meaningful learning of targeted concepts of microbiology. CBE-Life Sciences Education, 6(2), 155-162. https://doi.org/10.1187/cbe.06-12-0212.

March, J.G. (1991). Exploration and exploitation in organizational learning. Organization science, 2(1), 71-87.

Marks, M.A., Mathieu, J.E., Zaccaro, S. (2001). A temporally based framework and taxonomy of team processes. Academy of Management Review, 26(3), 356-376. https://doi.org/10.5465/AMR.2001.4845785.

Matz, R.L., \& Jardeleza, S.E. (2016). Examining the role of leadership in an undergraduate biology institutional reform initiative. CBE_Life Sciences Education, 15(4), ar57. https://doi.org/10.1187/cbe.15-10-0222 http:// www.lifescied.org/content/15/4/ar57.abstract.

Morgeson, F.P., DeRue, D.S., Karam, E.P. (2009). Leadership in teams: A functional approach to understanding leadership structures and processes. Journal of management, 36(1), 5-39.

O'Reilly III, C.A., Caldwell, D.F., Barnett, W.P. (1989). Work group demography, social integration, and turnover. Administrative Science Quarterly, 34(1), 21-37.

Pentland, A. (2014). Social physics: How good ideas spread-the lessons from a new science. New York: Penguin.

Reinholz, D.L., \& Apkarian, N. (2018). Four frames for systemic change in STEM departments. International Journal of STEM Education, 5(1), 3. https://doi. org/10.1186/s40594-018-0103-x https://stemeducationjournal. springeropen.com/articles/10.118.

Stasser, G., Vaughan, S.I., Stewart, D.D. (2000). Pooling unshared information: The benefits of knowing how access to information is distributed among group members. Organizational Behavior and Human Decision Processes, 82(1), 102-116. https://doi.org/10.1006/obhd.2000.2890 http://linkinghub. elsevier.com/retrieve/pii/S0749597800928905.

Wageman, R., Hackman, J.R., Lehman, E. (2005). Team diagnostic survey. The journal of applied behavior science, 41 (4). https://doi.org/10.1177/ $0021886305281984 \mathrm{http}: / / f i l e s / 54 /$ Wagemanetal2005Teamdiagnosticsurvey.pdf.

Weaver, G.C., Burgess, W.D., Childress, A.L., Slakey, L. (2016). Transforming institutions: Undergraduate STEM education for the 21st century. West Lafeyette: Purdue University Press. 
Wittenbaum, G.M., \& Stasser, G. (1996). Management of Information in Small Groups. In J.L. Nye \& A.M. Brower (Eds.), What's social about social cognition? (pp. 3-28). Thousand Oaks: SAGE Publications.

Woolley, A.W., Chabris, C.F., Pentland, A., Hashmi, N., Malone, T.W. (2010).

Evidence for a collective intelligence factor in the performance of human groups. Science, 330(October), 686-689.

\section{Submit your manuscript to a SpringerOpen ${ }^{\circ}$ journal and benefit from:}

- Convenient online submission

- Rigorous peer review

- Open access: articles freely available online

- High visibility within the field

- Retaining the copyright to your article

Submit your next manuscript at $\gg$ springeropen.com 